\title{
Effects of Culture on Economic Performance and Grassland Degradation
}

The Case of Tibetans and Mongolians in the Qinghai Lake Area

Tu Qin, Tan Shuhao, Nico Heerink and Qu Futian

\section{OpenEdition}

\section{Journals}

Electronic version

URL: http://journals.openedition.org/chinaperspectives/3683

DOI: $10.4000 /$ chinaperspectives.3683

ISSN: 1996-4617

\section{Publisher}

Centre d'étude français sur la Chine contemporaine

Printed version

Date of publication: 4 April 2008

Number of pages: $37-45$

ISSN: 2070-3449

\section{Electronic reference}

Tu Qin, Tan Shuhao, Nico Heerink and Qu Futian, «Effects of Culture on Economic Performance and Grassland Degradation », China Perspectives [Online], 2008/2 | 2008, Online since 01 April 2011, connection on 28 October 2019. URL : http://journals.openedition.org/chinaperspectives/3683 ; DOI 10.4000/chinaperspectives.3683 


\section{Effects of Culture on}

\section{Economic Performance and}

Grassland Degradation

The Case of Tibetans and Mongolians in the Qinghai Lake Area

TU QIN, TAN SHUHAO, NICO

HEERINK AND QU FUTIAN*

This study uses micro-level data gathered for Tibetans and Mongolians living in the same region (Qinghai Lake area in Northwest China) and having similar religion (Buddhism) and livelihoods (livestock raising) to examine how cultural differences between these two ethnic groups affect their integration into markets, their means of livestock production, and the extent of degradation of the grassland. We find significant cultural differences between the two ethnic groups, and conclude that the impact of religious attitudes on the market orientation of herder households is the dominating force explaining a relatively high degree of grassland degradation among Mongolian households.

\section{Introduction}

$\mathrm{C}$ ulture can be an important factor in economic growth, but the impact of culture on the economy has not attracted much research until recently. This neglect mainly stems from the broad and complex nature of culture, which makes it very difficult to measure the contribution of culture to economic performance. ${ }^{(1)}$ Culture is defined as those customary beliefs and values that ethnic, religious, and social groups transmit fairly unchanged from generation to generation. In other words, culture is a system of shared beliefs, values, customs, behaviour, and artefacts that the members of a society use to cope with their world and with one another, and that is transmitted from generation to generation through learning. ${ }^{(2)}$

In recent years, better methods and more data have made it possible to identify systematic differences in people's preferences and beliefs and to relate them to various measures of cultural factors. ${ }^{(3)}$ Many cross-country studies suggest that culture is a significant determinant of economic growth. For example, from a set of former colonies, Grier ${ }^{(4)}$ finds that Protestantism is significantly related to income and economic growth. Using the World Values Survey data, Guiso et al. ${ }^{(5)}$ find a positive relation between religious culture and economics. Noland ${ }^{(6)}$ confirms the positive effect of religious culture on economic outcomes, using national and regional religion as explanatory variables.

* $\quad$ We thank the Royal Netherlands Academy of Arts and Sciences, and the Chinese Ministry of Science and Technology for financial support. We are also very grateful to the MSc students from Qinghai Institute of Minority Studies who assisted us in data collection.

1. Avner Greif, "Culture Beliefs and the Organization of Society: A Historical and Theoretical Reflection on Collectivist and Individualist Societies," Journal of Political Economy, vol. 102, no 5, 1994, pp. 912-950; and Avner Greif, Institutions: Theory and History. Comparative and Historical Institutional Analysis, Cambridge, Cambridge University Press, 2005.

2. Luigi Guiso, Paola Sapienza and Luigi Zingales, "Does Culture Affect Economic Outcomes?" Journal of Economic Perspectives, vol. 20, no 2, 2006, pp. 23-48.

3. Luigi Guiso, Paola Sapienza, and Luigi Zingales, "Does Culture Affect Economic Outcomes?" op. cit.

4. Robin Grier, "The Effect of Religion on Economic Development: A Cross National Study of 63 Former Colonies," Kyklos vol. 50, 1997, pp. 47-62.

5. Luigi Guiso, Paola Sapienza and Luigi Zingales, "People's Opium? Religion and Economic Attitudes," Journal of Monetary Economics, vol. 50, 2003, pp. 225-282.

6. Marcus Noland, "Religion and Economic Performance," World Development, vol. 33, 2005, pp. 1215-1232. 
More recent studies on culture and economy focus on the dimensions of culture that can affect economic outcomes, and have arrived at two standard potential channels of influence - beliefs and values (i.e., preferences). ${ }^{(7)}$ Culture and economics may have two-way causal links, i.e. culture may affect economics and economics may affect culture. However, culture that is inherited by an individual from previous generations rather than voluntarily accumulated, such as religion and ethnic background, can largely be treated as exogenous for that individual's life. ${ }^{(8)}$

We add to the available literature, which is largely based on aggregate data at the country or regional level, by analysing the relationship between culture and economic outcomes at the household level for two ethnic groups living in the same region, namely Tibetans and Mongolians around Qinghai Lake in northwest China. The two groups have similar religious beliefs and livelihoods as Buddhist yak and sheep herders, but have maintained important differences in religious culture as we shall see below. The main objective of this paper is to examine how cultural differences between these two ethnic groups affect their integration into markets, their methods of livestock production, and the extent of degradation of the grassland. To this end, we first introduce the survey that we conducted in the area and examine the cultural differences between the two groups in section 2. In sections 3 and 4 we examine the impact on these cultural differences on selected socio-economic variables and on grassland degradation, respectively. We end with some concluding observations in section 5 .

\section{Cultural differences between Tibetans and Mongolians}

In this section, we will discuss the cultural differences between two ethnic groups, Tibetans and Mongolians, who live in the Qinghai Lake area. We will first describe the data collection and then present some descriptive statistics of differences between the two groups.

A survey among 242 herder households in the Qinghai Lake area was conducted in May 2007. There are four counties surrounding the lake, Haiyan, Gangcha, Tianjun, and Gonghe, covering a total of about 60 thousands $\mathrm{km}^{2}$. The households were randomly selected and interviewed in these four counties. After checking the data, it was found that the answers of 12 households could not be used. This gave a sample size of 230 herder households: 43 from Haiyan, 70 from Gangcha, 33 from Tianjun, and 84 from Gonghe County. According to the Statistical Yearbook of Qinghai, more than 80 percent of agricultural income is derived from livestock in these four counties. The per capita net income level of rural households in 2006 in these four counties ranged from 2,565 RMB to 3,227 RMB. As can be seen from Table 1, this level is slightly higher (9-37 percent) for all four counties than the average for the whole province (2,358 RMB).

Table 1. Per capita net income of rural households, Qinghai and four selected counties (RMB)

\begin{tabular}{|c|c|c|c|c|c|}
\hline Year & Haiyan & Gangcha & Tianjun & Gonghe & $\begin{array}{l}\text { Qinghai } \\
\text { Province }\end{array}$ \\
\hline 2002 & 1749 & 2382 & 2315 & 2164 & 1711 \\
\hline 2004 & 1937 & 2587 & 2653 & 2498 & 2005 \\
\hline 2005 & 2162 & 2827 & 2870 & 2693 & 2165 \\
\hline 2006 & 2565 & 3033 & 3227 & 2901 & 2358 \\
\hline
\end{tabular}

Source: Qinghai Bureau of Statistics, Qinghai tongji nianjian 2003-2007 (Qinghai Statistical Yearbook 2003-2007), Beijing, China Statistics Press.

Our questionnaire included detailed questions about a range of household characteristics, such as demographic status, asset ownership (land, livestock, house, etc.), education, income and consumption, trust, and religion, besides questions on income, consumption, ownership of nearby grazing lands, and communal matters.

The two main ethnic groups living in the area, Tibetans and the Mongolians, have different languages but have a similar livelihood and the same religion, Tibetan Buddhism. The herds of the households in this area consist mainly of yak and sheep. Nowadays, herder households build their houses at relatively low altitudes and relatively close to roads. The grassland close to the villages is normally used for livestock herding in the winter and in the spring, and is called winter/spring grassland. Grassland at higher altitudes is only accessible in the summer and autumn, and is called summer/autumn grassland. In most of the area, summer/autumn grassland is publicly accessible.

Table 2 presents some basic characteristics of the sampled households. Tibetans are the dominant ethnic group in the Qinghai Lake area. The Tibetans have significantly more grass-

7. Fabian Bornhorst, Andrea Ichino, Karl Schlag, and Eyal Winter, "Trust and Trustworthiness Among Europeans: South-North Comparison," C.E.P.R. Discussion Paper no 4378, London, Centre for Economic Policy Research, 2004; Luigi Guiso, Paola Sapienza and Luigi Zingales, "Does Culture Affect Economic Outcomes?" op. cit.

8. Maristella Botticini and Zvi Eckstein, "Jewish Occupational Selection: Education, Restrictions, or Minorities?" Journal of Economic History, vol. 65, no 4, 2005, pp. 922-48. 
Table 2. Characteristics of the sample

\begin{tabular}{|c|c|c|c|}
\hline & Tibetans & Mongolians & Total sample \\
\hline Number of households interviewed & 185 & 45 & 230 \\
\hline Number of persons & 911 & 206 & 1,117 \\
\hline Average household size & 4.92 & 4.58 & 4.86 \\
\hline Average size of grassland ${ }^{1}\left(m u^{2}\right)^{* *}$ & 971 & 664 & 911 \\
\hline Household consumption per capita (RMB) & 3,543 & 2,884 & 3,417 \\
\hline Number of yaks per household * & 34.8 & 26.1 & 33.1 \\
\hline Number of sheep per household & 203.1 & 221.7 & 206.8 \\
\hline Herd size per household (sheep units ${ }^{3}$ ) & 342.3 & 326.3 & 339.1 \\
\hline \multicolumn{4}{|c|}{$\begin{array}{l}\text { 1: Does not include summer/autumn grassland } \quad \text { 2: Fifteen mu }=\text { one hectare } \\
\text { 3: Following local tradition, one yak equals four sheep in the calculations of herd size } \\
\text { * Difference between group means for Tibetans and Mongolians is significant at } 5 \% \text { level; } \\
\text { * Difference between group means for Tibetans and Mongolians is significant at } 1 \% \text { level. }\end{array}$} \\
\hline Source: Authors' survey & & & \\
\hline
\end{tabular}

land than the Mongolians on average: 65 versus 44 hectares, respectively. The Tibetans also have slightly larger average family sizes and consumption levels ${ }^{(9)}$ than the Mongolians, but the differences are not statistically significant. Tibetans hold around 33 percent more yaks than Mongolians, but total herd sizes do not differ significantly for the two groups.

Our questionnaire included three questions about household efforts and input into religious activities: 1) money spent in the (local) temples (in RMB), 2) average time (in minutes) spent praying per day, and 3 ) the number of temple visits per year. In addition, three different questions were used to measure religious beliefs ${ }^{(10)}$ : 1) Do you believe in the three "crown jewels" of Buddhism: Buddha, Dharma and Sangha? 2) Do you think that your beliefs are useful in solving problems in your daily life? 3) Are you willing to give up some of your consumption now in order to have a better after-life? Respondents were asked to indicate the intensity of their beliefs on a 5-point scale ( 1 for "not at all," 5 for "fully").

Table 3 shows the differences between Tibetans and Mongolians in answering the questions on religious inputs and beliefs. Tibetans spent significantly more time than Mongolians at praying (at 5 percent level), and went significantly more times to temples (at 1 percent level), but financial inputs do not differ significantly between the two groups. On average, Tibetans spend more than double the time praying and visit temples twice as often as Mongolians do. Tibetans also score significantly higher on average than Mongolians (at 1 percent level) on all three questions relating to strength of religious beliefs.

Another relevant aspect of culture that may affect economic performance and resource degradation is the level of trust among Tibetans and Mongolians. To compare differences in trust between the two ethnic groups, we used the following question (taken from the General Social Survey): "Generally speaking, would you say that most people can be trusted, or that you can't be too careful in dealing with people?" Sociologists widely use this question to measure and compare the trust level between countries and over time. The percentage of respondents who answer "most people can be trusted" is used as the estimation of trust level. The results for our sample, presented in Table 4, show that Tibetans and Mongolians have similar trust levels. About twothirds of the respondents in both ethnic groups replied that "most people can be trusted."

We also examined the extent to which different groups (parents, brothers/sisters, children, relatives, neighbours, people in the same village, strangers, clergy) are trusted. To this

9. Because respondents did not like to answer the questions about income, the income data is not reliable. Instead, we use household consumption level as a proxy of economic performance.

10. These questions were composed after consultation with Prof. Kalsang Gyal, Institute of World Religions, Chinese Academy of Social Sciences, Beijing. He is an expert in Tibetan Buddhism. 
Table 3. Religious attitudes of Tibetans and Mongolians

\begin{tabular}{|c|c|c|c|}
\hline Aspect & Variable & Tibetans & Mongolians \\
\hline \multirow{3}{*}{ Religious inputs } & 1) Money spent in temples (RMB) & 494 & 585 \\
\hline & 2) Praying time per day (minutes) ${ }^{*}$ & 43.5 & 20.1 \\
\hline & 3) Number of temple visits per year ** & 5.1 & 2.0 \\
\hline \multirow{3}{*}{ Religious beliefs } & $\begin{array}{l}\text { 1) Believe in "three jewels" of Buddhism: Buddha, } \\
\text { Dharma and Sangha ** }\end{array}$ & 4.9 & 4.2 \\
\hline & $\begin{array}{l}\text { 2) Religion beliefs are useful to solve problems in } \\
\text { real life ** }\end{array}$ & 4.4 & 3.4 \\
\hline & $\begin{array}{l}\text { 3) In order to have a better after-life, give up } \\
\text { some consumption now ** }\end{array}$ & 3.5 & 2.7 \\
\hline
\end{tabular}

cantly higher for ethnic Mongolians. This finding indicates that Mongolians pay more attention to the education of their next generation than Tibetans do. The results of our survey further show that Mongolians master Mandarin significantly better than Tibetans. The poor mastery of Mandarin may be an important constraint on the integration of Tibetans into markets for livestock (and other products).

The differences in religious attitudes and in education levels are both likely to affect the involvement of the two ethnic groups in economic activities and their adoption of new technology to raising livestock. Table 7 shows the results relating to two questions on market orientation that were asked in our survey: "Can you sell products anytime you like," and "Are you willing to sell lambs." As many as 73 percent of the Mongolians answered that they can sell products anytime they like, compared with only 38 percent of the $\mathrm{Ti}$ betans. Because many Mongolians speak Mandarin fluently, they can contact the slaughterhouse in the capital city (Xining, about 300 kilometres away) and negotiate the price directly. When they think the price is good, they can arrange transportation together and sell their livestock to the slaughterhouse themselves. Most of the Tibetans, on the other hand, stay at home waiting for vendors to collect their yaks and sheep. This normally takes place in the autumn. If they miss the selling opportunity, they need to keep their livestock over the winter and spring. This period is very long and cold in the Qinghai Lake area, lasting about eight months with temperatures often reaching $-30^{\circ}$ or lower. Yaks and sheep are confined to winter/spring grassland and eat dried grass,
Table 4. Levels of trust among Tibetans and Mongolians (\%)

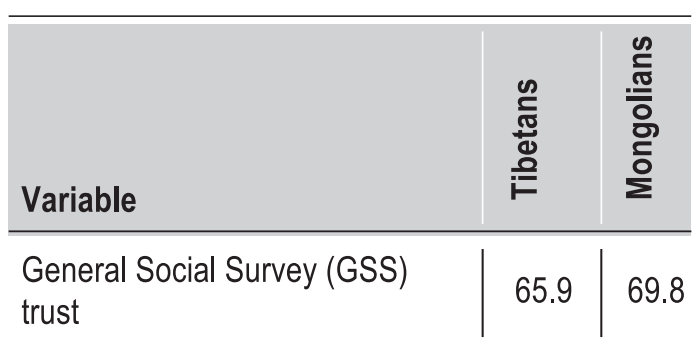

Trust in different groups of people:

\begin{tabular}{l|l|l} 
Parents & 98.5 & 97.0 \\
\hline Sisters and brothers & 91.3 & 87.4 \\
\hline Children & 89.6 & 86.8 \\
\hline Relatives $^{* *}$ & 84.8 & 76.9 \\
\hline Neighbors & 83.1 & 81.2 \\
\hline Herders in the same village ** & 77.0 & 67.3 \\
\hline Strangers & 32.0 & $\frac{28.1}{73.6}$ \\
\hline People related to religion $^{* *}$ & 84.0 & 73.0
\end{tabular}

*: Difference between group means is significant at $5 \%$ level;

**: Difference between group means is significant at $1 \%$ level.

Source: Authors' survey 
Table 5. Education levels of Tibetans, Mongolians and Han (six years and older)

\begin{tabular}{l|c|c|c|c|c}
\hline \hline Ethnic group & $\begin{array}{c}\text { Never went to } \\
\text { school (\%) }\end{array}$ & $\begin{array}{c}\text { Primary } \\
\text { school (\%) }\end{array}$ & $\begin{array}{c}\text { Secondary } \\
\text { school (\%) }\end{array}$ & $\begin{array}{c}\text { High school } \\
(\%)\end{array}$ & $\begin{array}{c}\text { University and } \\
\text { up (\%) }\end{array}$ \\
\hline Tibetans & 45.49 & 41.25 & 7.72 & 4.19 & 1.35 \\
\hline Mongolians & 7.23 & 37.99 & 34.72 & 14.84 & 5.23 \\
\hline Han & 7.26 & 39.29 & 37.31 & 12.23 & 3.90 \\
\hline
\end{tabular}

Source: Computed from the Fifth National Census (http://www.stats.gov.cn/tjs//ndsj/renkoupucha/2000pucha/html/t0202.htm)

and normally loose one-third to one-half of their body weight during this period. The livestock death rate is much higher than during other seasons. The best strategy in terms of production efficiency, therefore, is to sell all lambs that are not needed for reproduction before the end of the autumn. But due to strong religious beliefs, a majority of Tibetans (62 percent) are not willing to sell lambs. By contrast, only 31 percent of the Mongolians in the research area are unwilling to sell lambs.

The traditional life style in the Qinghai Lake area is primarily nomadic pastoralism. Livestock stay outside, even during very cold winters, and herders simply use the grassland without doing anything to improve it. To improve the productivity of grassland and efficiency of livestock production, two new technologies have been increasingly adopted in recent years. To reduce weight loss and death rate, livestock are kept in simple shelters or other refuges (such as greenhouses) during the winter and spring seasons. To increase the cover rate of grass and the productivity of grassland, degraded grassland is seeded with native types of grasses, and cultivated grassland is planted with gramineous forage grasses such as oats or highland barley. The adoption rates of these two new technologies among Tibetans and Mongolians are shown at the bottom of Table 7. We found that Mongolians are significantly more likely to use both technologies than Tibetans. Close to 90 percent of the Mongolians have adopted at least one of the two new technologies, compared with 60 percent of the Tibetans.

It can be concluded from the data presented in this section that Mongolians are more market-oriented and use better technologies for raising livestock than Tibetans. In the next section, we will examine whether these differences in economic behaviour affect pressure on the grassland.

\section{Effects of culture on grassland degradation}

Unfortunately, no data are available on grassland degradation for the area around Qinghai Lake. Table 8 shows range-

Table 6. Education levels of Tibetans and Mongolians

\begin{tabular}{|c|c|c|}
\hline Variable & Tibetans & Mongolians \\
\hline Years of education of household head & 2.0 & 1.3 \\
\hline Years of education: Age $>25$ years & 1.5 & 1.2 \\
\hline Years of education: Age between 16 and 25 years ** & 3.9 & 6.6 \\
\hline Percentage of children at school: Age between 7 and 15 years ** & $74 \%$ & $97 \%$ \\
\hline Level of Mandarin ${ }^{1 * *}$ & 0.9 & 1.9 \\
\hline $\begin{array}{l}\text { 1: } 0=\text { no, } 1=a \text { little, } 2=\text { good speaking, } 3=\text { can write } \\
*: \text { Difference between group means is significant at } 5 \% \text { level; } \\
\text { Source: Authors' survey }\end{array}$ & \multicolumn{2}{|c|}{ **: Difference between group means is significant at $1 \%$ level. } \\
\hline
\end{tabular}


land degradation in Qinghai Province as a whole, and compares this with three other provinces in western China. More than half (56 percent) of the natural grassland in Qinghai Province is degraded. This is slightly less than the degradation of grassland in Xinjiang and Inner Mongolia, but higher than the grassland degradation in Gansu Province. The severity of the degradation is relatively high in Qinghai Province: 22 percent of the degraded grassland suffers from severe degradation. This is much higher than in Xinjiang and Inner Mongolia, but slightly less than in Gansu Province.

Many factors cause rangeland degradation. In Western China, population growth and rising livestock prices have contributed to a rapid increase in the number of livestock held and a steep decline in the available rangeland area per livestock unit. During the past 50 years, on average, the number of livestock has increased 10 times, while the occupied rangeland area per livestock unit has decreased more than six times. ${ }^{(14)}$

Culture may have mixed effects on grassland degradation. On the one hand, strong religious beliefs cause Tibetans to use their grassland inefficiently. They do not like to sell lambs, even when winter is approaching, and are less likely to adopt new technologies such as refuges ${ }^{(15)}$ and grass planting (see previous section). As a result, Tibetan culture is likely to contribute to grassland degradation.

On the other hand, strong religious beliefs make Tibetans less market-oriented than Mongolians, as we saw in the previous section. As a consequence, Tibetans may keep less livestock than Mongolians, leading to less grassland degradation. As we discussed in section 2, the average Tibetan household has more rangeland (65 ha) than Mongolian households (44 ha) but maintains a similar herd size (342 and 326 standard sheep units, respectively). This means that the stocking rate equals 5.3 standard sheep units per hectare for Tibetan households and 7.4 standard sheep units per hectare for Mongolian households. Mongolian herders therefore impose a greater grassland pressure than Tibetan herders. Another reason why Tibetans may experience less grassland degradation than Mongolians has to do with differences in trust between the two groups. In section 2, we found that Tibetans have a higher trust in fellow villagers than Mongolians have. Trust is an essential pre-condition for the willingness of villagers to contribute to public good, such as the eradication of rats. Rats are a major cause of grassland degradation in the research area, and easily move from the land of one household to that of another. Cooperation between households within the same village is therefore cru-
Table 7. Market orientation and new technology adoption of Tibetans and Mongolians

\begin{tabular}{|c|c|c|}
\hline Variable & 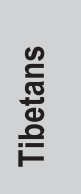 & 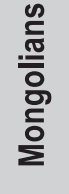 \\
\hline $\begin{array}{l}\text { Can you sell your products anytime } \\
\text { you like? }(1=\text { yes, } 0=\text { no })^{* *}\end{array}$ & 0.38 & 0.73 \\
\hline $\begin{array}{l}\text { Do you accept to sell lamb? } \\
(1=\text { yes, } 0=\text { no })^{* *}\end{array}$ & 0.38 & 0.69 \\
\hline $\begin{array}{l}\text { Household rate of using refuges to } \\
\text { shelter livestock ** }\end{array}$ & 0.41 & 0.64 \\
\hline Household rate of seeding grass * & 0.42 & 0.60 \\
\hline $\begin{array}{l}\text { Household rate either using refuges } \\
\text { or seeding grass ** }\end{array}$ & 0.61 & 0.89 \\
\hline
\end{tabular}

* Difference between group means is significant at $5 \%$ level;

${ }^{* *}$ Difference between group means is significant at $1 \%$ level.

Source: Authors' survey

cial for ending rat infestation, and mutual trust plays an important role in this respect.

The ultimate outcome of these two opposite forces, efficiency in grassland use versus market orientation and trust, depends on the relative size of each. Empirical evidence is needed to determine which of the two forces is stronger. We used information on self-reported grassland degradation collected in our survey to compare grassland degradation among Tibetan and Mongolian herder households. The results, listed in Table 9, clearly indicate that Mongolian households experience more grassland degradation than $\mathrm{Ti}$ betan households: The shares of grassland with no or slight degradation are higher for Tibetan households, while the shares of grassland with medium or severe degradation are higher for Mongolian households. The difference in average degradation is statistically significant at the 1 -percent level. The table further shows that Tibetans are significantly less involved in rat eradication than Mongolian households, de-

14. Hou Xiangyang (ed) Zhongguo caodi shengtai huanjing jianshe zhanlue yanjiu (Constructing rangeland ecological environment in China), Beijing, China Agricultural Press, 2005.

15. Sheep and yaks loose less weight when they are kept in a refuge in winter and spring As a result, the grass-to-meat conversion ratio and the pressure on the grassland will be lower as compared to animals that cannot use such refuges. 
Table 8. Rangeland degradation in four provinces in western China

\begin{tabular}{l|c|c|r|rrrr}
\hline \hline Province & $\begin{array}{c}\text { Natural } \\
\text { grassland } \\
\text { (million ha) }\end{array}$ & $\begin{array}{c}\text { Degraded } \\
\text { (million ha) }\end{array}$ & $\begin{array}{c}\text { Percentage } \\
\text { degraded }\end{array}$ & \multicolumn{2}{|c}{ Structure of degradation (\%) } \\
Qinghai & 36.37 & 20.37 & 56 & 42 & 36 & 22 \\
\hline Xinjiang & 57.26 & 34.67 & 61 & 48 & 38.5 & 13.5 \\
\hline Inner Mongolia & 78.80 & 46.73 & 59 & 52 & 37 & 11 \\
\hline Gansu & 17.90 & 8.56 & 48 & 36.5 & 39.8 & 23.7 \\
\hline Total & 190.33 & 110.33 & 58 & 47.9 & 37.4 & 14.7 \\
\hline
\end{tabular}

Source: Hou Xiangyang (ed) Zhongguo caodi shengtai huanjing jianshe zhanlue yanjiu

(Constructing rangeland ecological environment in China), op. cit.

Table 9. Grassland degradation and rats eradication among Tibetans and Mongolians

\begin{tabular}{|c|c|c|}
\hline & 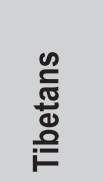 & 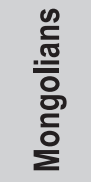 \\
\hline Total number of grassland plots & 279 & 103 \\
\hline Share of plots affected by: & & \\
\hline $0=$ no degradation & $10.4 \%$ & $2.9 \%$ \\
\hline 1 = slight degradation & $33.7 \%$ & $26.2 \%$ \\
\hline $2=$ medium degradation & $21.9 \%$ & $22.3 \%$ \\
\hline $3=$ severe degradation & $34.0 \%$ & $48.6 \%$ \\
\hline $\begin{array}{l}\text { Average degradation level of } \\
\text { grassland ** }\end{array}$ & 1.8 & 2.2 \\
\hline $\begin{array}{l}\text { Households suffering from rats } \\
\text { plague * }\end{array}$ & $95 \%$ & $86 \%$ \\
\hline $\begin{array}{l}\text { Household involved in rats } \\
\text { eradication ** }\end{array}$ & $41 \%$ & $77 \%$ \\
\hline
\end{tabular}

Note: Only winter/spring grassland is included.

* Difference between group means is significant at $5 \%$ level;

${ }^{* *}$ Difference between group means is significant at $1 \%$ level.

Source: Authors' survey spite the greater trust between Tibetan villagers (discussed in section 2). Strong religious beliefs make Tibetans object to the killing of rats, and as a result, Tibetan households suffer significantly more (at a 5 percent level) from rat infestation than Mongolian households do. We can therefore conclude that the lower degree of grassland degradation among Tibetan herders is not caused by a higher involvement in the eradication of rats, but is probably caused by the lower degree of market orientation as compared with Mongolian herders. This more than offsets the impact of culture on grassland efficiency, resulting in higher grassland degradation among Mongolian herders than among Tibetan herders.

\section{Conclusions}

This study expands the existing literature on culture and economic performance by examining micro-level data gathered for two ethnic groups (Tibetans and Mongolians) living in the same region (Qinghai Lake area in Northwest China) and having similar religion (Buddhism) and livelihoods (livestock raising). We find significant cultural differences between the two ethnic groups. Tibetans have much stronger religious beliefs than Mongolians and also devote a larger part of their lives to their religion. They also have more trust in fellow villagers, relatives, and clergy than Mongolians have, even though general levels of trust do not differ significantly between the two groups. These differences in religious attitudes and trust affect various social and economic aspects of their lives. We find that the education level of persons aged 16-25 and the school enrolment for children aged 7-15 are significantly higher for Mongolians than for Ti- 
betans, while the education levels of older age groups are similar for both ethnic groups. This finding indicates that Mongolians pay more attention to the education of their next generation than Tibetans do. We also find that Mongolians are more market-oriented and make more use of new technologies for raising livestock (refuges and planting grasses) than Tibetans.

Another novel aspect of our study is our examination of the impact of differences in religious attitudes and trust on grassland degradation. Our data on self-reported grassland degradation clearly indicate that Mongolian households experience more grassland degradation than Tibetan households. We also find that Tibetan households are less involved in eradication of rats, a major cause of grassland degradation in the research area, despite the larger trust of Tibetans in other villagers. Based on these findings, we conclude that the impact of religious attitudes on the market orientation of herder households is the dominating force explaining the relatively high degree of grassland degradation among Mongolian households.
Our findings have important implications for policy making. They imply that policies to promote sustainable economic development in the Qinghai Lake area should make a clear distinction between the two major ethnic groups, the Tibetans and the Mongolians. Policy measures to stimulate education of children should focus in particular on Tibetan households, and take into consideration the religious attitudes that make these households reluctant to invest in the next generation. Policy measures aimed at improving the integration of Tibetan herders into livestock markets run into the danger of increasing the pressure on the available grassland, as has recently occurred among Mongolian herders in the region. Effective policies aimed at mitigating the impact on grassland degradation may include public measures to counteract rat infestations resulting from Tibetan's reluctance to kill rats, and promoting the adoption of new technologies that increase the efficiency of livestock raising among Tibetan herders. 